\title{
Implementasi Program Asuransi Kesehatan Masyarakat Miskin di Nusa Tenggara Timur
}

\author{
Tri Rini Puji Lestari*
}

\begin{abstract}
Abstrak
Kesehatan merupakan hak asasi manusia, sehingga upaya pelayanan pengobatan untuk penduduk miskin tidak boleh dipandang sebagai sesuatu yang konsumsi, tetapi sebagai investasi untuk mencapai masyarakat yang sejahtera. Penelitian ini bertujuan mendapatkan informasi tentang akses penduduk miskin pada pelayanan rumah sakit melalui program Askeskin di Nusa Tenggara Timur (NTT). Penelitian menggunakan pendekatan kualitatif dengan informan kunci adalah pejabat di RSU Prof. DR. W.Z. Johannes NTT dan PT Askes cabang Kupang. Hasil penelitian memperlihatkan bahwa jumlah kartu yang diterbitkan tidak sesuai dengan realita jumlah maskin dan ada oknum tidak maskin yang menggunakan fasilitas Askeskin. Juga ditemukan beberapa obat yang tercantum dalam formularium Askeskin tidak tersedia pada saat dibutuhkan. Sehingga pasien miskin terpaksa diberi obat sejenis dari luar formularium dengan konsekuensi harga yang lebih mahal dan harus ditanggung oleh pihak rumah sakit karena tidak dapat diklaim. Selain itu, ketiadaan dukungan dana dari pemerintah daerah, mengakibatkan segala pembiayaan di luar pertanggungan Askeskin harus dibebankan pada rumah sakit penyelenggara pelayanan kesehatan.
\end{abstract}

Kata kunci : Asuransi kesehatan, masyarakat miskin, pelayanan kesehatan, akses

\begin{abstract}
Public health improvement, especially for under-privilege, needs more attention. Health issues should not be considered as a matter of mere consumption. Health should be viewed as an investment in order to achieve welfare as one of many faces of human rights. This research was aim at gathering information on the improvement of health access at the hospital designated for under-privilege through Askeskin by PT Askes in East Nusa Tenggara (NTT). The research used qualitative approach with key informants of official at Prof. DR. W.Z. Johannes General Hospital of NTT and PT Askes Kupang branch. The research shows that the total number of distributed cards was not a reflection of the actual number of poor people and there were individuals that not fall into poor category using Askeskin facilities. There were also finding on drugs other than formularium, which brought it to an increase in price and the hospital has to be responsible for the additional cost for they could not claim it. Moreover, there were no financial support from local government, causing a delay on the payment other than Askeskin and the health service provider, e.i. hospital held responsible to it.
\end{abstract}

Key words : Health insurance, poor people, health service, access

${ }^{*}$ Pusat Pengkajian Pengolah Data dan Informasi Setjen DPR RI, Gd. Nusantara I Lt. 2 Jl. Gatot Subroto Jakarta 10270 (e-mail : tririni@yahoo.com) 
Kemiskinan merupakan permasalahan yang kompleks karena menggantungkan penghidupan masyarakat pada kondisi alam yang berat dan sumber daya alam yang sangat terbatas. Namun, menurut data BPS, sejak tahun 2001, jumlah orang miskin di Indonesia memperlihatkan kecenderungan yang menurun. Sampai Februari tahun 2004, angka kemiskinan menurun menjadi 36,1 juta atau $16,6 \%$ dari total jumlah penduduk yang mencapai 217 juta. Jumlah penduduk miskin di daearah perkotaan adalah 11,5 juta $(12,6 \%)$ dan di daerah pedesaan 24,6 juta $(19,5 \%) .{ }^{1}$ Dibandingkan dengan tahun 2003 dengan angka kemiskinan 37,3 juta(17,42 \%), saat ini, jumlah orang miskin menurun sekitar 0,96\%. Perhitungan BPS tersebut didasarkan pada pemakaian kalori 2.100 per kapita per orang dan pencukupan kebutuhan non pangan. Setiap orang di wilayah perkotaan dan pedesaan yang mengkonsumsi kalori kurang dari standar tersebut dikelompokkan sebagai penduduk miskin. Sementara itu, seorang penduduk dinyatakan miskin apabila tak dapat memenuhi 28 kebutuhan hidup non pangan seperti kain, sabun, sikat gigi dan sebagainya.

Dalam upaya meningkatkan akses pelayanan kesehatan bagi masyarakat miskin, sejak Januari tahun 2005, Departemen Kesehatan meluncurkan Program Jaminan Pemeliharaan Kesehatan Masyarakat Miskin (PJKMM). Program tersebut merupakan reformasi program kesehatan bagi masyarakat miskin yang telah berlangsung sebelumnya seperti Jaring Pengaman Sosial Bidang Kesehatan (JBSBK) dan Program Penanggulangan Dampak Pengurangan Subsidi Energi (PDPSE) atau Bahan Bakar Minyak (PKPSBBM). Perbedaan mendasar antara PJKMM dengan program sebelumnya terletak pada pengelola dan mekanisme pengelolaannya. Sebelumnya, pengelolaan dilakukan secara langsung oleh Pemberi Pelayanan Kesehatan (PPK) atau tidak langsung oleh Badan Penyelenggara Jaminan Pemeliharaan Kesehatan Masyarakat yang berorientasi non-for-profit. Sedangkan program PJKMM dikelola seragam dan tersentralisir oleh PT. Askes. Kebijakan tersebut mengacu pada Keputusan Menteri Kesehatan No. 1241/Menkes/SK/XI/2004 dan Keputusan Menteri Kesehatan No. 56/Menkes/SK/I/2005 tentang Penyelenggaraan Program Jaminan Pemeliharaan Kesehatan Masyarakat Miskin tahun 2005.2

Hal tersebut sejalan dengan amanat Undang-Undang No. 40 tahun 2004 tentang Sistem Jaminan Sosial Nasional (SJSN) yang tertuang pada Pasal 19 ayat (1) bahwa Jaminan Kesehatan diselenggarakan secara nasional berdasarkan prinsip asuransi sosial dan prinsip ekuitas (keadilan). Pada ayat (2) ditentukan bahwa jaminan kesehatan diselenggarakan untuk menjamin agar peserta memperoleh manfaat pemeliharaan kesehatan dan perlindungan dalam memenuhi kebutuhan dasar kesehatan. Iuran program jaminan sosial bagi fakir miskin dan orang tidak mampu dibayar oleh pemerintah (Pasal 17 ayat (4). Dengan penetapan PT Askes sebagai pengelola dana subsidi bidang kesehatan bagi gakin, maka tantangan yang dihadapi adalah cara PT Askes melaksanakan tanggung jawab mengelola dana gakin yang dapat menjamin penerimaan pelayanan kesehatan tepat sasaran.

Berdasarkan fakta dilapangan, tunggakan pembayaran klaim asuransi kesehatan untuk keluarga miskin ke fasilitas pelayanan kesehatan tidak dapat dihindari. Kejadian tersebuti dipicu oleh keterlambatan pencairan dana pemerintah dan kelambanan proses verifikasi pemanfaatan askeskin. Selain itu, terjadi peningkatan pemanfaatan fasilitas askeskin yang menyebabkan dana yang tersedia tak mencukupi. Hingga 31 Desember 2006, kewajiban PT Askes mencapai Rp. 545 miliar. Sebagian kewajiban itu telah dilunasi dari sisa dana askeskin tahun 2006 sebesar Rp 126 miliar dengan tambahan uang muka yang telah disetor ke seluruh rumah sakit senilai $\mathrm{Rp}$. 171 miliar. Dengan demikian, masih ada kekurangan dana askeskin tahun 2006 sebesar Rp 248 miliar. $^{3}$

Penulis tertarik untuk mengetahui implementasi kebijakan pengentasan kemiskinan di bidang kesehatan dalam rangka meningkatkan akses pelayanan rumah sakit bagi masyarakat miskin melalui program di NTT.

\section{Metode}

Penelitian dilakukan dengan menggunakan pendekatan kualitatif dengan studi kasus, untuk mendapatkan informasi yang mendalam tentang pelaksanaan asuransi kesehatan bagi masyarakat miskin di RSU Prof. DR. W.Z. Johannes NTT. Data primer didapat dengan melakukan wawancara mendalam pada informan kunci yaitu para pejabat di RSU Prof. DR. W.Z. Johannes NTT dan PT Askes cabang Kupang. Adapun fokus penelitiannya adalah telaah pelaksanaan program Askeskin oleh PT Askes di RSU Prof. DR. W.Z. Johannes NTT. Informan pada penelitian ini meliputi: 1) para pejabat di RSU Prof. DR. W.Z. Johannes NTT yang terdiri dari direktur RS, kepala bagian (Kabag) Keuangan RS, Kabag. Unit Rawat jalan, Kabag. Unit Rawat Inap, Kabag. Farmasi, dan Kabag. Rekam Medis; 2) para pejabat di PT Askes cabang Kupang yang terdiri dari Kepala Cabang PT. Askes dan Kabag. Keuangan PT Askes cabang Kupang.

Data dikumpulkan dengan menggunakan metode wawancara mendalam dengan menggunakan instrumen pedoman wawancara mendalam. Wawancara dilakukan atas persetujuan para informan. Untuk menjaga validitas data digunakan triangulasi sumber. Data yang didapat dilakukan pengolahan dengan membuat catatan lapangan menjadi transkrip, melakukan analisis dan interpretasi dengan menggunakan metode analisis isi. Analisis temuan penelitian juga didukung dengan data sekunder yang didapat dari instansi tersebut di atas, BPS, surat kabar dan bahan-bahan kepustakaan lainnya. 


\section{Hasil}

Secara umum Nusa Tenggara Timur (NTT) merupakan salah satu provinsi termiskin di Indonesia. Tingkat kemiskinan di propinsi ini lebih tinggi dari rata-rata tingkat kemiskinan nasional. Data BPS 2004 menyebutkan bahwa jumlah penduduk miskin Indonesia mencapai $17 \%$, sementara jumlah penduduk miskin di NTT adalah $28 \%$.

Di bidang kesehatan, NTT dihadapkan pada masalah penyakit menular, khususnya malaria dan TBC (tuberculosis), kematian ibu melahirkan dan kematian bayi yang tinggi. Kasus malaria dan TBC yang tinggi memengaruhi kondisi kesehatan dan produktivitas masyarakat dan menyebabkan kematian ibu melahirkan yang tinggi. Selain itu, kematian ibu melahirkan yang tinggi juga dipengaruhi oleh cara pertolongan persalinan. Survei Demografi dan Kesehatan Indonesia (SDKI) 2002/2003 di NTT menemukan bahwa meskipun program bidan desa telah dikembangkan, $72 \%$ kelahiran dilakukan di rumah dan $54,2 \%$ kelahiran ditolong oleh dukun beranak. ${ }^{4}$ Status gizi balita pada tahun 2004 menunjukkan status gizi sedang $(28,65 \%)$ dan status gizi buruk $(15,68 \%)$. Proporsi balita dengan status gizi sedang dan buruk relatif besar serta tingkat kematian balita yang juga relatif tinggi (49 kematian per 1000 kelahiran). Hal ini mengindikasikan bahwa kemampuan orang tua mengupayakan kesehatan yang lebih baik bagi anaknya relatif terbatas sebagai akibat kemampuan ekonomi serta pendidikan yang rendah. ${ }^{4}$

Perbaikan sistem pelayanan kesehatan pada tahun 2007 dilakukan melalui dua program utama meliputi: Pertama, program pengadaan, peningkatan dan perbaikan sarana dan prasarana kesehatan melalui kegiatan pembangunan 38 pustu, rehabilitasi 29 pustu, 7 puskesmas dan 1 pengadaan sarana dan prasarana puskesmas, pustu dan pusling. Kedua, Program Kemitraan, Peningkatan Pelayanan Kesehatan melalui "Pemberian Jaminan Kesehatan khususnya bagi 78.524 jiwa penduduk miskin yang belum terdata dalam Askeskin”. Secara keseluruhan, kebijakan peningkatan sistem pelayanan kesehatan menyerap dana sekitar Rp. 44 Milyar (10\%) dari total dana perimbangan sekitar 18,6 Milyar yang dialokasikan untuk penyediaan sarana prasarana kesehatan, (sekitar Rp. 4 Milyar untuk membayar tambahan penghasilan 4.239 tenaga medis dan gaji para medis (sekitar Rp. 21 Milyar).

\section{Pelaksanaan Program Askeskin \\ Kebijakan Kepesertaan}

Penetapan keluarga miskin sebagai peserta program Askeskin didasarkan pada kuota Menteri Kesehatan. Setelah mendapat pengesahan dari Bupati/Walikota, PT. Askes berhak mengeluarkan kartu peserta Askeskin. Namun, data dari Pemerintah Daerah Kabupaten/Kota yang dikirim ke PT. Askes belum dilengkapi dengan nama peserta sehingga memperlambat proses penerbitan kartu peserta Askeskin. Walau demikian, selama belum memiliki kartu peserta Askeskin, peserta dapat menggunakan Kartu Sehat, Kartu JPK-Gakin atau Surat Keterangan Tidak Mampu (SKTM) dari kelurahan tempat penduduk miskin berdomisili. Jumlah penduduk maskin pada periode 2005 - 2007 adalah: pada tahun 2005 (1.152.085 jiwa), tahun 2006 (2.652.342 jiwa) dan tahun 2007 (2.798.871 jiwa).

Di lapangan ditemukan seorang pasien yang datang berobat ke rumah sakit dengan menggunakan mobil memiliki Kartu Sehat. Dalam kasus seperti ini. biasanya pihak rumah sakit tidak dapat berbuat banyak, tetap melayani sesuai prosedur pelayanan pasien Maskin di rumah sakit. Selain itu, pernah juga ditemukan pasien yang pada awal masuk rumah sakit menggunakan Kartu sehat dan dirawat di ruang rawat kelas III, tetapi setelah beberapa lama pasien tersebut mengajukan pindah ke ruang rawat VIP. Pernah juga ditemukan pasien yang masuk rumah sakit dengan membawa Kartu Sehat atau JPKGakin, tetapi ketika akan dirawat inap dengan fasilitas ruang rawat kelas III mereka menolak dan memilih tidak menggunakan fasilitas Maskin serta memilih dirawat di ruang selain kelas III.

Penelitian juga menemukan bahwa tidak sedikit pasien yang semula berobat ke rumah sakit ternyata tidak mampu dan tidak mempunyai Kartu Sehat, Kartu JPKGakin atau SKTM. Apabila pasien harus di rawat, biasanya pasien diizinkan dirawat dan keesokan harinya keluarga pasien harus mengurus SKTM sebagai kelengkapan administrasi. Namun, tidak jarang pasien yang tidak mampu tersebut, merupakan rujukan lintas kabupaten dan tidak mampu membiayai kehidupan keluarga sehari-hari selama keluarga di rumah sakit apalagi untuk ongkos mengurus SKTM di wilayah domisili mereka. Dalam kondisi seperti ini, tidak jarang pihak rumah sakit membebaskan pasien dari pembiayaan yang harus ditanggung.

\section{Kebijakan Pelayanan Rumah Sakit Masyarakat Miskin}

Dalam melaksanakan pembayaran biaya pelayanan rumah sakit, PT. Askes cabang Kupang mengacu pada Pedoman Pelaksanaan Jaminan Pemeliharaan Kesehatan Masyarakat Miskin Departemen Kesehatan. Dengan demikian pelayanan kesehatan dilakukan secara komprehensif sesuai kebutuhan medis dan ketersediaan dana di fasilitas kesehatan yang bekerjasama dengan PT. Askes, terutama fasilitas kesehatan pemerintah. Sistem pelayanan kesehatan yang diterapkan menggunakan pendekatan konsep wilayah (desentralisasi), sistem rujukan terstruktur dan berjenjang, penjagaan mutu dan pengendalian biaya, gawat darurat di fasilitas kesehatan terdekat. Berbagai pihak yang terlibat meliputi unsur pemerintah daerah, unsur pusat pelayanan kesehatan dan unsur lain. 
Unsur pemerintah daerah meliputi Dinas Kesehatan Provinsi dan Kabupaten/Kota, Badan Pusat Statistik Provinsi dan Kabupaten/Kota, BKKBN Provinsi dan Kabupaten/ Kota, Bappeda Provinsi dan Kabupaten/Kota dan Dinas Sosial Provinsi dan Kabupaten/Kota. Unsur Pusat Pelayanan Kesehatan (PPK) meliputi Puskesmas, RSU Pemerintah, RS Swasta, RS POLRI dan Apotik. Unsur lain meliputi legislatif (DPR/DPRD) dan Lembaga Swadaya Masyarakat (LSM).

Mekanisme kerja berupa koordinasi berbagai pihak terkait sesuai Keputusan Gubernur NTT No. 294/KEP/HK/2006 tentang Pembentukan Sekretariat Bersama Tim Koordinasi dan Forum Komunikasi Program Jaminan Pemeliharaan Kesehatan bagi Masyarakat Miskin (JPKMM)/Askeskin Provinsi Nusa Tenggara Timur. Kegiatan koordinasi dilakukan melalui pertemuan tim koordinasi di tingkat Provinsi/ Kabupaten/Kota secara berkala dan pertemuan terbatas dengan instansi terkait sesuai kebutuhan.

Agar dapat menggunakan fasilitas pelayanan kesehatan bagi masyarakat miskin di rumah sakit, pasien harus melengkapi persyaratan berbagai persyaratan berikut: Pasien Maskin dengan kasus non gawat darurat harus membawa surat rujukan dari Puskesmas yang disertai kartu peserta Maskin. Pasien yang belum memiliki kartu peserta Maskin, dapat menggunakan SKTM dan diberikan kesempatan untuk mengurus SKTM selambatlambatnya dalam waktu 2 × 24 jam; Untuk pasien Maskin dengan kasus Gawat dan Darurat, dapat langsung dilayani di unit gawat darurat tanpa harus membawa surat rujukan dengan syarat menunjukkan kartu peserta Maskin/SKTM. Semua persyaratan tersebut harus diserahkan diloket Askes (gabungan antara Askes maskin, sosial dan sukarela).

Fasilitas rawat jalan yang didapat oleh pasien maskin berupa semua pelayanan kesehatan dasar sesuai kebutuhan dan standar pelayanan seperti, pemeriksaan medis, obat-obatan sesuai formulir maskin, tindakan medik dan non medik (sesuai indikasi), pemeriksaan penunjang sesuai indikasi (laboraturium, radiologi, dll), dan rujukan ke sarana pelayanan yang lebih tinggi (sesuai indikasi) dengan biaya ambulan ditanggung rumah sakit. Fasilitas rawat inap yang didapat oleh pasien maskin berupa semua pelayanan kesehatan dasar sesuai kebutuhan dan strandar pelayanan seperti, akomodasi, makan-minum, obat-obatan sesuai formularium Askeskin, tindakan medik dan non medik (sesuai indikasi), pemeriksaan penunjang sesuai indikasi (laboraturium, radiologi, dll), dan rujukan ke sarana pelayanan yang lebih tinggi (sesuai indikasi) dengan biaya ambulan ditanggung rumah sakit.

Berkaitan dengan pelayanan pemberian obat pada pasien, seringkali pihak rumah sakit dihadapkan pada item obat yang yang tidak tercantung dalam formularium obat maskin (seperti Amoxycicilin capsul 500 mg/injek- si 1 gram, Ampicilin injeksi, dan lain-lain; atau adrenalin, atropin sulfat, dan lain-lain). Akibatnya, pihak rumah sakit terpaksa memberikan obat diluar formularium obat maskin yang sejenis, tetapi dengan harga yang lebih mahal dan harus di tanggung oleh rumah sakit.

\section{Kebijakan Keuangan}

Sumber dana pelayanan kesehatan bagi masyarakat miskin hanya berasal dari APBN/Pemerintah Pusat. Dana untuk pelayanan kesehatan maskin di Rumah Sakit disalurkan oleh Departemen Kesehatan melalui PT. Askes (Persero) untuk pelayanan Rawat Jalan Tingkat Lanjut (RJTL), Rawat Inap Tingkat Lanjut (RITL), obat dan transportasi rujukan.

Pelaksanaan klaim dilakukan setelah pihak rumah sakit mengentri semua data periode satu bulan dari tanggal 1 sampai tanggal 31 . Kemudian, data tersebut diverifikasi oleh petugas Askes yang khusus ditempatkan di rumah sakit. Pengajuan klaim dilakukan setiap tanggal 10 sampai tanggal 15 bulan berikutnya dan dana turun sekitar 3 sampai 4 bulan setelah diajukan. Contohnya: tagihan bulan Januari 2006, klaim diajukan pada tanggal 15 Pebruari 2006 dan realisasi pembayaran dilakukan pada tanggal 18 Mei 2006 dan 24 Juni 2006, sesuai besaran klaim yang diajukan. Selama realisasi pembayaran belum diturunkan, pihak rumah sakit harus menanggung biaya terlebih dahulu. Kondisi tersebut menjadi tantangan pihak rumah sakit untuk tetap menjalankan kegiatan operasional rumah sakit dengan menutupi kebutuhan biaya dari sumber dana yang lain. Hal tersebut dilakukan melalui subsidi silang paviliun swasta.

Pengajuan klaim dilakukan berdasarkan pada jenis kelamin, jumlah biaya yang dikeluarkan oleh rumah sakit sesuai Surat Keputusan Bersama Menteri Kesehatan dan Menteri Dalam Negeri No. 616A/Menkes/SKB/VI/ 2004 dan No. 155a/tahun 2004. Realisasi klaim yang diajukan pihak rumah sakit kepada PT. Askes, biasanya baru dapat diwujudkan bila dana dari Departemen Kesehatan sudah turun. Penelitian juga menemukan bahwa PT. Askes tidak menyediakan uang muka untuk biaya transportasi pasien yang dirujuk, semua biaya tersebut dibebankan pada pihak rumah sakit. Selain itu, sampai saat ini masih belum ada alokasi dana khusus untuk mensubsidi biaya pelayanan kesehatan masyarakat miskin yang tidak terakomodasi dalam paket pelayanan Askeskin, seperti untuk obat-obatan, tindakan medis, rujukan, dan lain-lain. Pihak Pemerintah Daerah NTT masih membebankan biaya tersebut pada rumah sakit.

\section{Pembahasan}

Kesehatan merupakan faktor yang sangat penting dalam kehidupan manusia sehingga negara berkewajiban 
memelihara kesehatan rakyat. Penunjukkan PT Askes sebagai lembaga pengelola program Askeskin masih menuai kekecewaan pihak rumah sakit yang memberikan pelayanan kesehatan. Selain itu, acuan data yang digunakan ada perbedaan ketentuan kuota penduduk miskin, Pemerintah Pusat dalam menentukan berdasarkan data jumlah penduduk maskin per kepala keluarga, sementara menentukannya berdasarkan jumlah masyarakat miskin per jiwa. Akibatnya, jumlah masyarakat miskin yang ada di daerah lebih banyak daripada jumlah kuota peserta Askeskin yang sudah ditentukan oleh Pemerintah Pusat. ${ }^{5}$ Fakta tersebut mengakibatkan Pemerintah Daerah harus menanggung semua biaya pelayanan kesehatan yang tidak termasuk dalam jumlah kuota maskin. Pemerintah Daerah NTT yang tidak tergolong kaya tidak mampu untuk menanggung anggaran tersebut. Agar pelayanan kesehatan bagi masyarakat miskin tetap dapat dilaksanakan, semua pembiayaan pelayanan kesehatan bagi Maskin di rumah sakit dibebankan pada RSU Prof. DR. W.Z. Johannes.

Seringkali pihak rumah sakit dihadapkan pada tidak tersedianya item obat yang tercantum dalam formularium obat maskin (Amoxycicilin capsul 500 mg/injeksi 1 gram, Ampicilin injeksi, dan lain-lain; atau adrenalin, atropin sulfat, dan lain-lain). Akibatnya pihak rumah sakit terpaksa memberikan obat diluar formularium obat maskin yang sejenis dengan harga yang lebih mahal dan harus di tanggung oleh rumah sakit karena tidak dapat diklaim.

Salah satu sebab kemiskinan di Provinsi NTT antara lain disebabkan oleh penghidupan masyarakat yang sangat tergantung pada kondisi alam yang berat dan sumber daya alam yang sangat terbatas. Akibatnya masyarakat NTT mengalami ketertinggalan yang tercermin pada rendahnya tingkat pendapatan, angka kemiskinan yang tinggi, dan tingkat pendidikan, kesehatan, dan akses terhadap kondisi kehidupan layak yang rendah. ${ }^{4}$ Selain itu, jumlah kuota peserta Askeskin yang relatif lebih rendah daripada jumlah masyarakat miskin yang ada, menyebabkan pembengkakan anggaran yang harus ditanggung pihak rumah sakit. Hat tersebut dapat juga membuka peluang pemanfaatan fasilitas Askeskin oleh pihak-pihak yang tidak memenuhi kriteria masyarakat miskin (Maskin). Temuan di tentang oknum tidak maskin yang memiliki Kartu Sehat dan memanfaatkan fasilitas Askeskin merupakan salah satu bukti bahwa pemanfaatan Askeskin belum tepat sasaran. Menghadapi kasus seperti itu, biasanya pihak rumah sakit berada dalam posisi yang terjepit. Karena berpengaruh pada cash flow rumah sakit yang pada akhirnya mempengaruhi kegiatan operasional rumah sakit. Bagi pihak rumah sak, Kondisi seperti ini merupakan dilema, di satu sisi pihak rumah sakit harus tetap memberikan pelayanan bagi Maskin, tetapi dilain pihak rumah sakit juga mem- punyai keterbatasan dana operasional.

Faktor lain yang memberatkan pihak rumah sakit adalah belum ada subsidi dana transportasi pasien yang dirujuk. Padahal, berdasarkan hasil wawancara pihak PT Askes dan buku Pedoman Pelaksanaan Jaminan Pemeliharaan Kesehatan Masyarakat miskin pelayanan transportasi untuk rujukan emergency, rujukan non emergency yang diperlukan dan pemulangan pasien/jenazah maskin merupakan salah satu fasilitas yang dapat diterima dalam program Askeskin. Hal ini menunjukkan bahwa tidak semua fasilitas yang tersedia dalam program Askeskin dapat dinikmati oleh maskin dan jika harus dilaksanakan tidak dapat diajukan klaim sehingga harus dibebankan pada rumah sakit.6-8

Jumlah obat yang termasuk dalam DPHO sangat terbatas, sehingga pihak rumah sakit harus mengganti dengan obat-obatan diluar DPHO dengan harganya yang lebih mahal tersebut membuat beban pihak rumah sakit semakin besar. Banyak obat-obatan yang termasuk dalam DPHO yang tidak tersedia di pasaran menghambat pelayanan kesehatan yang diberikan pihak rumah sakit. Hal lain yang dapat menghambat pemberian pelayanan kesehatan adalah pedoman pelaksanaan yang terlambat sampai setelah 4 bulan program berjalan. Kondisi ini tidak sejalan dengan kebijakan makro strategis pemerintah yang diterjemahkan kedalam Kebijakan Makro Operasional atau Program Utama, sebagai berikut: Penyakit menular dan gangguan gizi banyak menyerang penduduk miskin sehingga memerlukan pelayanan kesehatan dasar dan rujukan secara gratis pada penduduk miskin. ${ }^{9}$

Hal lain yang terkait kebijakan kepesertaan adalah jumlah kuota yang tidak disertai dengan nama dan identitas maskin. Hal tersebut mengakibatkan Pemerintah Daerah harus melakukan pendataan ulang yang berakibat pada perlambatan proses penerbitan kartu peserta Askin ke masyarakat. Selama belum memiliki kartu peserta Askeskin, masyarakat miskin dapat menggunakan Kartu Sehat, Kartu JPK-Gakin atau Surat Keterangan Tidak Mampu (SKTM) dari kelurahan tempat Maskin berdomisili.

Pengajuan klaim sampai dana klaim diturunkan memerlukan waktu rata-rata $3-4$ bulan dan dana yang turun tidak $100 \%$. Hal tersebut menyebabkan beban tambah bagi pihak rumah sakit. Karena pihak rumah sakit harus membiayai terlebih dahulu operasional pelaksanaan pelayanan kesehatan maskin. Selain itu, petugas PT Askes di rumah sakit yang masih kurang dan belum ada petugas PT Askes di rumah sakit yang bertugas 24 jam, juga merupakan penghambat dalam proses pegajuan klaim.

Kebijakan keuangan yang berkaitan penyelenggaraan program Askeskin, di Provinsi NTT yang tidak tergolong 
kaya, sumber dana hanya berasal dari APBN yang disalurkan oleh Departemen Kesehatan melalui PT. Askes. Dana tersebut digunakan untuk pelayanan Rawat Jalan Tingkat Lanjut (RJTL), Rawat Inap Tingkat Lanjut (RITL), obat dan transportasi rujukan. Hal tersebut berbeda dengan Provinsi Bali yang mendapat bantuan dana dari APBD Propinsi dan APBD Kabupaten. Akibatnya talangan dana klaim yang belum turun dibeban pada ketersediaan dana yang dimikili oleh pihak rumah sakit. Keterbatasan dana pihak rumah sakit akan berdampak pada penurunan kualitas pelayanan rumah sakit yang akan diberikan. Kondisi ini menjadi dilema pihak rumah sakit, di satu sisi rumah sakit mempunyai kewajiban sosial untuk memberikan pelayanan kesehatan bagi maskin. Namun, di sisi lain pihak rumah sakit juga mempunyai kebutuhan agar operasional rumah sakit tetap berjalan.

Temuan lain yang berkaitan dengan kebijakan keuangan adalah perhitungan lama rawat inap yang digunakan pihak Askes dengan pihak rumah sakit berbeda. Akibatnya selalu ada selisih penghitungan yang seharusnya ditanggungkan menjadi tidak ditanggung oleh Askes yang dibebankan pada pihak rumah sakit. Kebijakan keuangan lain yang berbeda dengan kondisi di lapangan dan membebani pihak rumah sakit adalah biaya pemeriksaan penunjang pasien rawat jalan yang hanya ditanggung satu kali pemeriksaan oleh Askes. Padahal, pada kenyataannya seringkali pasien rawat jalan memerlukan lebih dari satu kali pemeriksaan penunjang.

\section{Kesimpulan}

Sejak Januari 2006, program program pelayanan kesehatan maskin yang dikelola oleh PT Askes persero mencakup pelayanan kesehatan dasar di Puskesmas dan jaringannya serta pelayanan rujukan di rumah sakit. Beberapa kendala yang mengganggu kelancaran pelaksanaan program tersebut antara lain terkait dengan kebijakan kepesertaan, jumlah kartu yang diterbitkan tidak sesuai dengan realita jumlah maskin. Selain itu, ditemukan juga oknum yang bukan maskin yang menggunakan fasilitas Askeskin. Beberapa obat dalam formularium Askeskin tidak tersedia ketika dibutuhkan, sehingga harus diberikan obat sejenis di luar formularium yang lebih mahal dan harus ditanggung oleh pihak rumah sakit. Di Provinsi NTT program pelayanan kesehatan bagi maskin tidak mendapatkan dukungan dana dari Pemerintah Daerahnya. Akibatnya, dana pertanggungan dibebankan pada pihak rumah sakit. Bagaimanapun, program pelayanan kesehatan bagi maskin yang dikelola PT Askes berkontribusi besar membantu maskin mendapatkan hak pelayanan kesehatan di rumah sakit.

\section{Saran}

Penentuan kuota kepesertaan bagi penduduk miskin sebaiknya mengacu pada penghitungan oleh pemerintah daerah. Selain itu, penentuan jumlah maskin sebaiknya didasarkan pada jumlah maskin per-jiwa, bukan jumlah maskin per-kepala keluarga dan perlu dipertimbangkan juga indikator khusus untuk maskin yang sesuai dengan budaya setempat. Perlu penjabaran lebih lanjut kebijakan umum yang dijadikan pedoman pelaksanaan pemberian pelayanan kesehatan bagi maskin. Berbagai kebijakan lokal pelayanan kesehatan bagi maskin di rumah sakit dapat tetap dimasukkan dalam pertanggungan Askeskin. Selain itu, fleksibilitas kebijakan pendanaan dan penyelenggaraan pelayanan kesehatan bagi maskin perlu disesuai dengan kemampuan daerah.

\section{Daftar Pustaka}

1. BPS. Jumlah penduduk miskin turun. [diakses tanggal 16 Agustus 2007]. Diunduh dari: http://www.tempointeraktif.com.

2. Badan Litbang Depkes RI. Laporan penelitian asesmen determinan utilisasi, askes dan kepuasan konsumen pel.kes, khusunya pada masyarakat miskin di daerah sulit, terpencil dan daerah miskin perkotaan. Cisarua: Litbang Depkes RI; 2006.

3. Asuransi Kesehatan. Tunggakan askeskin. [diakses tanggal 30 Maret 2007]. Diunduh dari: http://www.kompas.co.id

4. Widjajanti S. Tantangan pembangunan di Nusa Tenggara Timur. Jurnal SMERU. 2006; 20.

5. Arifianto \& Ruly. Program jaminan pemeliharaan kesehatan bagi keluarga miskin. Jakarta: Diklat Metodologi Penelitian Sosial Ekonomi; 2005.

6. Departemen Kesehatan RI. Pedoman penyelenggaraan program jaminan pemeliharaan kesehatan bagi masyarakat miskin tahun 2005. Jakarta: Departemen Kesehatan RI; 2005.

7. Departemen Kesehatan RI. Pedoman pelaksanaan jaminan pemeliharaan kesehatan bagi masyarakat miskin (Askeskin) tahun 2006. Jakarta: Departemen Kesehatan RI; 2006.

8. Departemen Kesehatan RI. Pedoman pelaksanaan jaminan pemeliharaan kesehatan bagi masyarakat miskin (Askeskin) tahun 2007. Jakarta: Departemen Kesehatan RI; 2007.

9. [diakses tanggal 2 Mei 2005]. www.//bppt.go.id/rakorbangnas03/depkes4.pdf. 